\title{
Evidence based post-operative treatment of flexor tendons
}

\author{
Sarah Ewald \\ From 10th Congress of the Asia-Pacific Federation of Societies of Surgery fo the Hand and the 6th Congress \\ of Asia-Pacific Federation of Societies of Hand Therapists \\ Kuala Lumpur, Malaysia. 2-4 October 2014
}

Flexor Tendon injuries require surgical repair and intensive therapy post-operatively for optimal outcomes. "The repair technique is important but it is the way the tendon is managed afterwards that determines the outcome" ([1], page 112). Multiple protocols exist for the post-operative rehabilitation of tendon injuries. Currently four main options for post-operative treatment are utilized: immobilization, early passive mobilization, early active-passive mobilization and earlyactive mobilization. Early protected movement has been shown to decrease adhesion formation and stimulate tendon healing [2]. It is well established that protected early movement of the tendon results in a better outcome than immobilization [3-5]. There is less risk of tendon rupture with early passive motion protocols, but an increased risk for decreased range of motion in the final outcome, in comparison to early active motion protocols [6].

"The goal of tendon repair and rehabilitation is to achieve a normally gliding and functioning tendon."([1], $\mathrm{p}$ 115). To achieve this goal the surgeon, the therapist and the patient must work closely together. The surgeon must create a repair that is strong enough to withstand the rehabilitation phase. The therapist must have a thorough understanding of: tendon anatomy, the mechanical limitations of the repair, the healing process and the biomechanical forces at work during the healing process. Additionally the therapist must understand the tendon's response to the chosen treatment and continually adjust the treatment accordingly. The patient too must participate in the treatment; this requires that the patient receives sufficient instruction that allows him or her to understand the injury and participate in the subsequent rehabilitation process.

In many clinics, flexor tendon rehabilitation is protocol driven; a standard post-operative protocol is implemented

City Handtherapie, Zurich, 8006, Switzerland routinely for flexor tendon injury cases. This approach may work well when the patient meets the standard inclusion criteria. However when the patient does not meet the criteria for the prescribed protocol for post-operative treatment, treatment of acute flexor tendon injuries can be a challenge and if not adjusted for may result in less than optimal outcomes. "Functional outcomes do not depend on following a prescribed protocol, but on progressing each patient individually with the available evidence-based information and on observation of the individual's healing process" [7]. There is ample evidence available to guide therapists and physicians in clinical decision making when patient characteristics do not fit the protocol. A review of evidence that supports and guides the therapist's clinical decision making in rehabilitation of the flexor tendon will be presented. Options for clinical situations such as: delayed initiation of post-operative treatment, concomitant injuries and or conditions that require rest vs. movement, patients that cannot follow complex treatment programs and other clinical scenarios that require an adapted approach to obtain an optimal outcome, will be discussed.

Published: 19 May 2015

\section{References}

1. Amadio PC: Friction of the gliding surface: implications for tendon surgery and rehabilitation. Journal of Hand Therapy 2005, 18(2):112-119.

2. Groth GN: Pyramid of progressive force exercises to the injured tendon. Journal of Hand Therapy 2004, 17:31-39.

3. Chesney A, Chauhan A, Kattan A, Farrokhyar F, Thoma A: Systematic review of flexor tendon rehabilitation protocols in zone II of the hand. Plastic Reconstructive Surgery 2011, 117:1583-192.

4. Tanaka T, Amadio PC, Zhao C, Zobitz ME, An KN: Flexor digitorumprofundus tendon tension during finger manipulation: a study in human cadaver hands. Journal of Hand Therapy 2005, 18(3):330-338.

5. trickland JW, Glogovac SV: Digital function following repair in zone II: a comparison of immobilization and controlled passive motion techniques. Journal of Hand Surgery 1980, 5A:537-43. 
6. Starr HM, Snoddy M, Hammond KE, Seiler JG: Flexor tendon repair rehabilitation protocols: a systematic review. Journal of Hand Surgery 2013, 38A:1712-1717.

7. Vucekovich KV, Gallardo G, Fiala K: Rehabilitation after flexor tendon repair, reconstruction and tenolysis. Hand Clinics 2005, 21:257-265.

doi:10.1186/1753-6561-9-S3-A109

Cite this article as: Ewald: Evidence based post-operative treatment of flexor tendons. BMC Proceedings 2015 9(Suppl 3):A109.

Submit your next manuscript to BioMed Central and take full advantage of:

- Convenient online submission

- Thorough peer review

- No space constraints or color figure charges

- Immediate publication on acceptance

- Inclusion in PubMed, CAS, Scopus and Google Scholar

- Research which is freely available for redistribution

Submit your manuscript at www.biomedcentral.com/submit
C Biomed Central 